\title{
Measurement of Anteroposterior diameters of normal brainstem by Magnetic Resonance Imaging
}

\author{
Singh $\mathbf{S}^{1^{*}}$, Sharma $\mathbf{B R}^{2}$, Bhatta $\mathbf{M}^{3}$, PoudelN ${ }^{2}$ \\ 'Lecturer/B.Sc. MIT Program Coordinator, ${ }^{2}$ Lecturer, Department of Radiology, ${ }^{3}$ B.Sc. MIT Student, Department of Radiology. \\ Gandaki Medical College \& Teaching Hospital, Pokhara, Nepal
}

\author{
Keywords \\ Brain stem, Corticomedullary, \\ Medulla oblongata, Mesencephalon, \\ MRI, and Pons.

\section{Corresponding author} \\ *Sushma Singh \\ Lecturer, B.Sc. MIT Program coordinator \\ Department of Radiology, \\ Gandaki Medical College \& Teaching \\ Hospital, Pokhara, Nepal \\ Email: forssbrt@gmail.com
}

\begin{abstract}
Aim: The aim of this study is to assess the anteroposterior diameter of brainstem (midbrain, pons and medulla) of normal Nepalese people to establish normal ranges and to correlate the measurement with patient's age and gender.

Method: The study is a cross-sectional prospective study which is performed in Gandaki Medical College, Pokhara. The data is collected over the period of 5 months from May 2018 to September 2018. The data of total 103 patients are collected who underwent (Magnetic Resonance Imaging) MRI head. Measurements of sagittal diameter at predefined levels i.e. distance between upper border of pons to midway between superior and inferior colliculi (A) for midbrain, distance between anterior surface of pons to the floor of fourth ventricle (B) for pons and anteroposterior diameter perpendicular to the long axis of medulla just above the posterior kink at cervicomedullary junction for medulla oblongata were made and noted.
\end{abstract}

Result: The mean anteroposterior diameter of midbrain, pons and medulla oblongata was found to be $1.7048 \pm 0.12 \mathrm{~cm}, 2.27 \pm 0.13 \mathrm{~cm}$ and 1.3 $\pm 0.088 \mathrm{~cm}$ respectively. The average ratio of sagittal diameter of pons to sagittal diameter of midbrain was $1.34 \pm 0.099 \mathrm{~cm}$ and average ratio of sagittal diameter of pons to medulla oblongata was $1.75 \pm 0.123 \mathrm{~cm}$.

Conclusion: There was no statistically significant correlation of the sagittal diameter of midbrain, pons and medulla with patient's gender. The sagittal diameter of brainstem reached maximum at the age 20 and stopped increasing. The sagittal diameter of midbrain and medulla oblongata decreased slightly after the age of 50 and decreased significantly after the age of 70 . There was no decrease in the sagittal diameter of pons after age.

\section{INTRODUCTION}

Brainstem is the relay centre of the human brain which connects the spinal cord with the cerebrum. Previous studies were obtained regarding the brain neuro anatomic studies and ages effect, using advanced imaging technology. Linear measurements can be made rapidly without additional hardware or software and is suggested to be a reliable method to evaluate the size of brainstem. Investigations of aging effects on the brain stem are important, not only to understand normal aging, but also for comparative study of the pathophysiology of degenerative brain disorders. ${ }^{1}$ Previous studies carried among normal individuals have shown that there are no significant differences in the size of brainstem between 
males and females. ${ }^{2,3}$ Some studies have concluded that the changes in brainstem diameters according to age are non-significant. ${ }^{2,4}$ Whereas other suggests that there is significant decrease in the size of brainstem with age. ${ }^{3}$ Some studies have described certain growth patterns of brainstem among different agegroup. ${ }^{5}$

Various pathological disease and syndromes are known involving brainstem. Cerebellar and brain stem atrophy are important features in Spinocerebellar Ataxia type-3. Recent neuropathologic studies have described additional brain stem involvement in Spinocerebellar Ataxia type$6{ }^{6}$ The size and diameter of brainstem is decreased in atrophy and increased in gliomas. Measurements of brain diameter may be valuable in tumors or atrophic processes involving this part of the central nervous system. It is likely that some diffusely infiltrating tumors may be detected by changes in the size of the midbrain rather than by demonstration of differences in the signals due to changes in relaxation times. ${ }^{7}$ Mid-sagittal MRI measurements of the midbrain area are reliable diagnostic criteria that can differentiate progressive supra nuclear palsy from other common extra pyramidal syndromes and normal aging. The mid-sagittal MRI measurements of the midbrain area can differentiate PSP from PD, MSAP and normal aging and these radiological measurements correlated well with the clinical aspects of the PSP syndrome. ${ }^{8}$ MR based measurements are simple and reliable method with high sensitivity and specificity to identify PSP. ${ }^{9}$ The midsagittal mesencephalic diameter measured on standard routine T2-weighted MR images can be used as a reliable measure to differentiate between patients with typical PD and those with PSP in vivo. ${ }^{10}$

The aim of this study is to develop a method of measuring the size of the brain stem by routine MRI and to determine brain stem dimensions in a normal population. Having knowledge about normal growth pattern and variations among different age group and gender can be helpful in determining pathological variations in the diameter of brainstem including neurodegenerative diseases.

\section{METHOD}

This is a cross sectional observational study, conducted at Gandaki Medical College Teaching Hospital \& Research Centre (GMCTHRC), Pokhara-Lekhnath metropolitan city, Kaski.
Sample:

The study sample includes 103 patients who were referred to MRI and all normal MRI head scans were taken under the study and; all MRI with altered signal intensities in brainstem were excluded. Patients with no known pathologies or abnormalities of brainstem were included.

Patients with known pathologies or abnormalities of brain stem, non nepalese patients, uncooperative patients and MRI scans with significant noise and artifacts were excluded from the study.

The method of sampling is judgment sampling (nonprobability sampling method) and period for sample collection was March 2018 to September 2018 (6 months).

All patients were examined using MRI machine SEIMENS MAGNETOM ESSENZA 1.5 Tesla MRI. Protocol used was T1 weighted sagittal image with TR- $500 \mathrm{~ms}$, TE- $8.9 \mathrm{~ms}$, Slice thickness- $5 \mathrm{~mm}$, distance factor $30 \%$ of slice thickness, Concatenations- 1, FOV 230 and FOV phase $100 \%$.

\section{Sampling technique:}

The method of sampling is judgement sampling (nonprobability sampling) method.

Data collection:

Performa was made to collect the measured values of anteroposterior diameter of midbrain, pons and medulla oblongata. Measurements were made on $\mathrm{T} 1$ weighted sagittal image at three different levels, i.e. distance between upper border of pons to midway between superior and inferior colliculi (A) for midbrain, distance between anterior surface of pons to the floor of fourth ventricle (B) for pons and anteroposterior diameter perpendicular to the long axis of medulla just above the posterior kink at cervicomedullary junction for medulla oblongata. Patient was positioned supine with sagittal reference line at mid sagittal plane of head and axial scan line at glabella. 


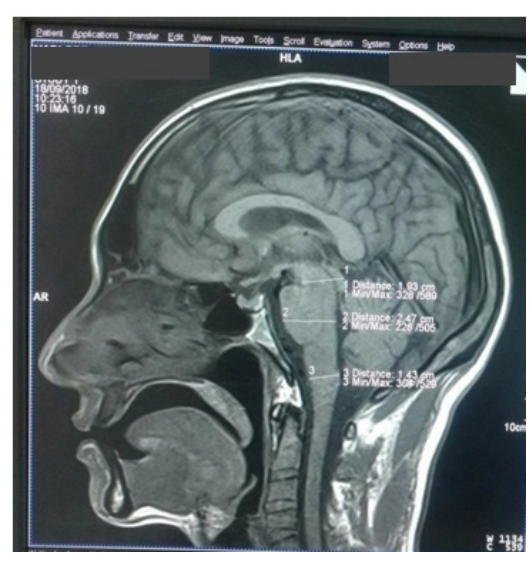

Figure 1: Sagittal T1 weighted image taken from SIEMENS MAGNETOM

ESSENZA 1.5 Tesla with measurements of anteroposterior diameter of brainstem

\section{Data analysis}

Statistical analyses were carried out with the help of SPSS version 25 and Microsoft Excel. The mean, standard deviation, and correlation between anteroposterior diameters of midbrain, pons and medulla at above mentioned levels and pons to midbrain ratio and pons to medulla ratio was calculated and the values were compared between different age group, and gender and the results were expressed in tables, figures and the scatter plot diagrams. For inferential data, independent sample T-tests were applied to correlate the measurements with gender and age.

\section{Correlation}

Correlation is the statistical technique that can show whether and how strongly pairs of variables are related. Correlation works for quantifiable data in which numbers are meaningful, usually quantities of some sort. It cannot be used for purely categorical data. Pearson's correlation coefficient also referred as Pearson's r, Pearson productmoment correlation coefficient or bivariate correlation, is a measure of the linear correlation between two variables $\mathrm{X}$ and $\mathrm{Y}$. It is the covariance of the two variables divided by the product of their standard deviations.

"r" value

The main result of correlation is called correlation coefficient (or " $r$ "). It ranges from -
1.0 to +1.0 . The closer the $r$ is to +1 or -1 , the more closely the two variables are related. If $r$ is close to 0 , it means there is no relationship between the variables. If $r$ is positive, it means that the two variables are directly related. Whereas if $r$ is negative, it means that the two variables are indirectly related (often called as inverse correlation).

\section{RESULTS}

The data was collected from 103 test subjects with no known brainstem abnormalities, 51 male and 52 females with age ranging from 8 years to 81 years. Patient's age, gender, anteroposterior diameters at the level of midbrain, pons and medulla oblongata, pons to midbrain ratio and pons to medulla ratio was recorded. Detailed results and outputs are shown in the tables and figures below.

Table 2: Distribution of Sample according to gender

\begin{tabular}{lcc}
\hline Gender & Frequency & Percentage \\
\hline Male & 51 & $49.5 \%$ \\
Female & 52 & $50.5 \%$ \\
Total & 103 & $100 \%$ \\
\hline
\end{tabular}

Table 3: Distribution of sample according to different age groups

\begin{tabular}{ccc}
\hline Age groups & Frequency & Percent \\
less than 20 & 14 & $13.6 \%$ \\
$20-29$ & 9 & $8.7 \%$ \\
$30-39$ & 19 & $18.4 \%$ \\
$40-49$ & 12 & $11.7 \%$ \\
$50-59$ & 13 & $12.6 \%$ \\
$60-69$ & 14 & $13.6 \%$ \\
70 and above & & \\
& & \\
Total & 103 & $100 \%$ \\
\hline
\end{tabular}


Table 4: Maximum, Minimum, mean and standard deviations of mesencephalic diameter, pontine diameter medullary diameter, pons to midbrain ratio and pons to medulla ratio

\begin{tabular}{|c|c|c|c|c|c|}
\hline Variables & $\mathbf{N}$ & $\begin{array}{l}\text { Mini- } \\
\text { mum }\end{array}$ & $\begin{array}{l}\text { Maxi- } \\
\text { mum }\end{array}$ & Mean & $\begin{array}{l}\text { Std. Devia- } \\
\text { tion }\end{array}$ \\
\hline $\begin{array}{l}\text { Mesencephalic } \\
\text { diameter }\end{array}$ & 103 & 1.46 & 1.98 & 1.7048 & 0.11989 \\
\hline Pontine diameter & 103 & 1.99 & 2.63 & 2.2739 & 0.13223 \\
\hline $\begin{array}{l}\text { Medullary diam- } \\
\text { eter }\end{array}$ & 103 & 1.08 & 1.51 & 1.3032 & 0.08833 \\
\hline $\begin{array}{l}\text { Pons to Mid- } \\
\text { brain Ratio (B/A) }\end{array}$ & 103 & 1.13 & 1.61 & 1.3385 & 0.09912 \\
\hline $\begin{array}{l}\text { Pons to Medulla } \\
\text { Ratio }(B / C)\end{array}$ & 103 & 1.42 & 2.10 & 1.7502 & 0.12263 \\
\hline
\end{tabular}

Table 5: Mean and Standard deviations of diameter of midbrain, pons and medulla oblongata with respect to gender

\begin{tabular}{lcccc}
\hline sex & Mesencephalic & $\begin{array}{c}\text { Pontine diam- } \\
\text { diameter }\end{array}$ & $\begin{array}{c}\text { Medullary } \\
\text { diameter }\end{array}$ \\
Male & 1.7000 & 2.2796 & 1.3159 \\
& $\mathrm{~N}$ & 51 & 51 & 51 \\
& $\begin{array}{c}\text { Std. } \\
\text { Devia- } \\
\text { tion } \\
\text { Mean }\end{array}$ & 0.12991 & 0.11269 & 0.08909 \\
& $\begin{array}{c}\text { Meal } \\
\text { Female }\end{array}$ & 1.7094 & 2.2683 & 1.2908 \\
& $\begin{array}{c}\text { N } \\
\text { Std. } \\
\text { Devia- } \\
\text { tion }\end{array}$ & 0.11027 & 52 & 52 \\
\hline
\end{tabular}

Table 6: Mean and Standard deviations of diameter of pons to midbrain ratio and pons to medulla ratio with respect to gender

\begin{tabular}{lccc}
\hline Sex & & $\begin{array}{c}\text { Pons to Midbrain Ratio } \\
\text { (B/A) }\end{array}$ & $\begin{array}{c}\text { Pons to Medulla Ratio } \\
\text { (B/C) }\end{array}$ \\
Male & Mean & 1.3467 & 1.7382 \\
& $\begin{array}{c}\text { Std. Devia- } \\
\text { tion } \\
\text { Female }\end{array}$ & 0.09941 & 0.11973 \\
& Mean & 1.3303 & 1.7619 \\
& $\begin{array}{c}\text { Std. Devia- } \\
\text { tion }\end{array}$ & 0.09913 & 0.12545 \\
\hline
\end{tabular}

Table 7: correlation and P value of age, diameters of pons, medulla and midbrain, pons to medulla ratio and pons to midbrain ratio with age

\begin{tabular}{|c|c|c|c|c|c|c|}
\hline & & $\begin{array}{l}\text { Mesen- } \\
\text { cephalic } \\
\text { diameter }\end{array}$ & $\begin{array}{l}\text { Pon- } \\
\text { tine } \\
\text { diame- } \\
\text { ter }\end{array}$ & $\begin{array}{l}\text { Med- } \\
\text { ullary } \\
\text { diame- } \\
\text { ter }\end{array}$ & $\begin{array}{c}\text { Pons to } \\
\text { Midbrain } \\
\text { Ratio } \\
(\mathrm{B} / \mathrm{A})\end{array}$ & $\begin{array}{l}\text { Pons to } \\
\text { Medul- } \\
\text { la Ratio } \\
(B / C)\end{array}$ \\
\hline \multirow[t]{2}{*}{ Age } & $\begin{array}{l}\text { Pearson Cor- } \\
\text { relation }\end{array}$ & $-0.434^{* *}$ & 0.103 & -0.137 & $0.504^{* *}$ & $0.221^{*}$ \\
\hline & Sig. (2-tailed) & $<0.001$ & 0.301 & 0.169 & $<0.001$ & 0.025 \\
\hline
\end{tabular}

Table 8: Table showing mean and standard deviations of AP diameters of midbrain, pons and medulla oblongata, pons to midbrain ratio and pons to medulla ratio on the basis of different age groups

\begin{tabular}{|c|c|c|c|c|c|c|}
\hline \multicolumn{2}{|c|}{ Age Groups } & \multirow{2}{*}{$\begin{array}{c}\text { Mesen- } \\
\text { cephalic } \\
\text { diameter } \\
1.7357\end{array}$} & \multirow{2}{*}{$\begin{array}{c}\begin{array}{c}\text { Pontine } \\
\text { diame- } \\
\text { ter }\end{array} \\
2.2136\end{array}$} & \multirow{2}{*}{$\begin{array}{c}\text { Med- } \\
\text { ullary } \\
\text { diameter } \\
1.2950\end{array}$} & \multirow{2}{*}{$\begin{array}{c}\text { Pons to } \\
\text { Midbrain } \\
\text { Ratio } \\
\text { (B/A) } \\
1.2779\end{array}$} & \multirow{2}{*}{$\begin{array}{c}\begin{array}{c}\text { Pons to } \\
\text { Medulla } \\
\text { Ratio } \\
(B / C)\end{array} \\
1.7148\end{array}$} \\
\hline & Mean & & & & & \\
\hline$<20$ & $\begin{array}{l}\text { Std. Devia- } \\
\text { tion }\end{array}$ & 0.10689 & 0.14216 & 0.10486 & 0.08880 & 0.11282 \\
\hline & Mean & 1.7778 & 2.2567 & 1.3233 & 1.2721 & 1.7103 \\
\hline $\begin{array}{l}20- \\
29\end{array}$ & $\begin{array}{l}\text { Std. Devia- } \\
\text { tion }\end{array}$ & 0.12387 & 0.12787 & 0.09987 & 0.07240 & 0.11017 \\
\hline & Mean & 1.7684 & 2.2758 & 1.3184 & 1.2900 & 1.7326 \\
\hline $\begin{array}{c}30- \\
39\end{array}$ & $\begin{array}{l}\text { Std. Devia- } \\
\text { tion }\end{array}$ & 0.10725 & 0.10292 & 0.08745 & 0.07459 & 0.12549 \\
\hline & Mean & 1.7342 & 2.3242 & 1.3250 & 1.3419 & 1.7555 \\
\hline $\begin{array}{l}40- \\
49\end{array}$ & $\begin{array}{l}\text { Std. Devia- } \\
\text { tion }\end{array}$ & 0.08554 & 0.14241 & 0.08085 & 0.08836 & 0.07834 \\
\hline & Mean & 1.6708 & 2.2985 & 1.3285 & 1.3770 & 1.7337 \\
\hline $\begin{array}{c}50- \\
59\end{array}$ & $\begin{array}{l}\text { Std. Devia- } \\
\text { tion }\end{array}$ & 0.09412 & 0.14439 & 0.06149 & 0.07391 & 0.13825 \\
\hline & Mean & 1.7186 & 2.3057 & 1.2907 & 1.3432 & 1.7915 \\
\hline $\begin{array}{c}60- \\
69\end{array}$ & $\begin{array}{l}\text { Std. Devia- } \\
\text { tion }\end{array}$ & 0.12184 & 0.15174 & 0.08544 & 0.05500 & 0.14039 \\
\hline & Mean & 1.5955 & 2.2555 & 1.2682 & 1.4183 & 1.7846 \\
\hline$\geq 70$ & $\begin{array}{l}\text { Std. Devia- } \\
\text { tion }\end{array}$ & 0.09226 & 0.12211 & 0.09027 & 0.11367 & 0.12781 \\
\hline
\end{tabular}


Table 9: Independent sample t-test between male and female

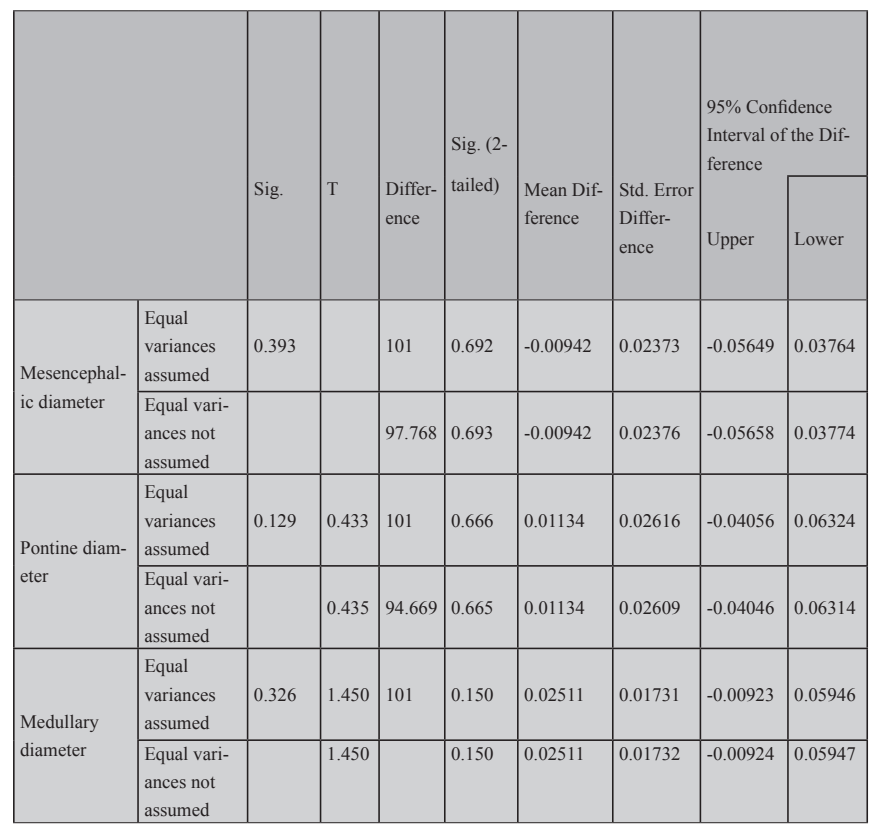

The mean, standard deviation, maximum and minimum values of anteroposterior diameter of midbrain, pons and medulla oblongata, pons to midbrain ratio and pons to medulla ratio was calculated and presented in table 3 .

The mean values of anteroposterior diameter of midbrain, pons and medulla oblongata were measured to be $1.7048 \pm$ $0.12 \mathrm{cms}, 2.27 \pm 0.13 \mathrm{cms}$ and $1.3 \pm 0.088 \mathrm{cms}$ respectively. The mean values of pons to midbrain ratio was $1.34 \pm$ $0.099 \mathrm{cms}$ and pons to medulla ratio was $1.75 \pm 0.123 \mathrm{cms}$ (table 3).

Correlation analysis of different variables was done with age. The results are presented in Table 8. At level of significance 0.01 , there was significant correlation of mesencephalic diameter with age. The correlation was negative. $(r=-0.434, \mathrm{P}<0.01)$.

There was significant positive correlation of pons to midbrain ratio (B/A) with age at level of significance 0.01 . ( $r=0.504, \mathrm{P}<0.01)$. At level of significance 0.05 , there was significant positive correlation of pons to medulla ratio with age. $(r=0.221, \mathrm{P}=0.25)$

There was no significant correlation of pontine diameter and medullary diameter with age. (Table 8) Independent sample T-test was performed to check whether there is significant difference in the mean anteroposterior diameters of midbrain, pons and medulla between males and females. This study found that there was no significant differences of anteroposterior diameter of mesencephalon $\left(\mathrm{T}_{(101)}=-0.393, \mathrm{P}=0.692\right)$, anteroposterior diameter of pons $\left.\mathrm{C}_{(101)}=0.433, \mathrm{P}=0.660\right)$ and anteroposterior diameter of medulla oblongata $\left(\mathrm{T}_{(101)}=1.45, \mathrm{P}=0.15\right)$ between males andfemales.

\section{DISCUSSION}

The objective of this study was to assess the anteroposterior diameter of brainstem (midbrain, pons and medulla oblongata). The measurements of diameters between upper border of pons to midway between superior and inferior colliculi (A) for midbrain, distance between anterior surface of pons to the floor of fourth ventricle (B) for pons and anteroposterior diameter perpendicular to the long axis of medulla just above the posterior kink at cervicomedullary junction was taken of Nepalese by using sagittal T1 images using 1.5 tesla MRI at Gandaki MedicalCollege.

A total of 103 subjects were taken in which 51 (49.5\%) were male and 52 (50.5\%) were female (Table1). The age of the patients ranged from 8 years to 81 years with average age 47.37. The minimum sample size taken for similar study was four ${ }^{2}$ and the maximum was $275^{5}$

Suh et al. concluded that there was no statistical difference of each dimension between male and female, and among different ages supporting the conclusions made in this study. ${ }^{3}$ Rahiget $\mathrm{al}^{4}$ concluded in his study that there was no significant correlation of the anteroposterior diameter of brainstem with gender supporting my study. In his study, he concluded that the diameter of brainstem decreased with age.

The diameter of midbrain was found to decrease with respect to age which is supported by the study done by Nagwan Elhussein et al. ${ }^{5}$ which concluded that brainstem aging- associated degeneration seems to be confined to the midbrain. A study done by Raininko et $\mathrm{al}^{6}$ concluded that there was no significant correlation of the diameters with patient's gender supporting my study.A study conducted by Murshed et $\mathrm{al}^{7}$ found that larger brain stem in males, which explains the correlation between supratentorial larger brain size in males and the brain stem structures.

In a study done by Looi ${ }^{11}$ linear and volumetric analysis 
was done of different brain structures with respect to age. This study concluded that there was highly significant age related decline in linear and cross-sectional area measurements of midbrain and no significant decline in pons and medulla supporting the conclusions of this study.

\section{CONCLUSION}

The mean anteroposterior diameter of midbrain, pons and medulla oblongata was found to be $1.7048 \pm 0.12$ $\mathrm{cm}, 2.27 \pm 0.13 \mathrm{~cm}$ and $1.3 \pm 0.088 \mathrm{~cm}$ respectively. The average ratio of sagittal diameter of pons to sagittal diameter of midbrain was $1.34 \pm 0.099 \mathrm{~cm}$ and average ratio of sagittal diameter of pons to medulla oblongata was $1.75 \pm 0.123 \mathrm{~cm}$.

There was no statistically significant correlation of the sagittal diameter of midbrain, pons and medulla with patient's gender. There mesencephalic diameter of the decreases with age, probably due to age related atrophy. But there was no statistically significant correlation of pontine diameter and medullary diameter with age.

\section{REFERENCES}

1. Elhussein N, Alkhathami AH, Ayad CE. Norms for Brain Stem: A morphometric MRI Based Study.

2. Suh JO, Joo YG, Suh SJ. MR measurement of normal brainstem diameter in Korean adults. Journal of the Korean Radiological Society. 1990 Aug 1;26(4):653-7.

3. Elameen E, Abd RA. Measurement of Normal Brainstem Diameter in Sudanese Population using MRI. Masters Thesis. Sudan University of Science \& Technology; 2016.

4. Murshed KA, Ziylan T, Seker M, Cicekcibasi A, Acikgozoglu S. Morphometric assessment of brain stem und cerebellar vermis with midsagittal MRI: the gender differences and effects of age. Neuroanatomy. 2003;2:35-8.
5. Raininko R, Autti T, Vanhanen SL, Ylikoski A, Erkinjuntti T, Santavuori P. The normal brain stem from infancy to old age. Neuroradiology. 1994 Jul 1;36(5):364-8.

6. Eichler L, Bellenberg B, Hahn HK, Köster O, Schöls L, Lukas C. Quantitative assessment of brain stem and cerebellar atrophy in spinocerebellar ataxia types 3 and 6: impact on clinical status. American Journal of Neuroradiology. 2011 May 1;32(5):890-7.

7. Koehler PR, Haughton VM, Daniels DL, Williams AL, Yetkin Z, Charles HC, Shutts D. MR measurement of normal and pathologic brainstem diameters. American journal of neuroradiology. 1985 May 1;6(3):425-7.

8. Emam AT, El-Sayed MA, Awad FM. Progressive supranuclear palsy: brainstem measurement and its clinical implication. Egypt J NeurolPsychiatNeurosurg. 2010;47:355.

9. Massey LA, Jäger HR, Paviour DC, O'Sullivan SS, Ling H, Williams DR, etal. The midbrain to pons ratio: a simple and specific MRI sign of progressive supranuclear palsy. Neurology. 2013 May 14;80(20):1856-61.

10. Warmuth-Metz M, Naumann M, Csoti I, Solymosi L. Measurement of the midbrain diameter on routine magnetic resonance imaging: a simple and accurate method of differentiating between Parkinson disease and progressive supranuclear palsy. Archives of neurology. 2001 Jul 1;58(7):1076-9.

11. Looi JC, Sachdev PS. Structural neuroimaging of the ageing brain. In: The Ageing Brain 2003. CRC Press. pp. 59-72. 